Research Article

\title{
Hospital Premises as a Potential Reservoir of Antimicrobial Resistance
}

\author{
Debasish Chattopadhya', Leimapokpam Sumitra Devi², Rajendra Singh Rautela ${ }^{3}$, \\ Shyam Sunder Grover ${ }^{4}$, Shobha Broor \\ 1,2,5 Department of Microbiology, SGT Medical College Hospital and Research Institute, Gurugram, Haryana, India. \\ ${ }^{3}$ Division of Biochemistry, National Centre for Disease Control, New Delhi, India. \\ ${ }^{4}$ Division of Microbiology, National Centre for Disease Control, New Delhi, India. \\ DOI: https://doi.org/10.24321/0019.5138.202104
}

\section{I $\quad \mathbf{N} \quad \mathbf{F} \quad \mathbf{O}$}

\section{Corresponding Author:}

Debasish Chattopadhya, Department of Microbiology, SGT Medical College Hospital and Research Institute, Gurugram, Haryana, India.

E-mail Id:

dchattopadhya27@gmail.com

Orcid Id:

https://orcid.org/0000-0002-4117-3050

How to cite this article:

Chattopadhya D, Devi LS, Rautela RS, Grover SS, Broor S. Hospital Premises as a Potential Reservoir of Antimicrobial Resistance. J Commun Dis 2021; 53(1): 15-22.

Date of Submission: 2021-01-01

Date of Acceptance: 2021-03-21

\section{$\begin{array}{llllllll}\mathbf{A} & \mathbf{B} & \mathbf{S} & \mathbf{T} & \mathbf{R} & \mathbf{A} & \mathbf{C} & \mathbf{T}\end{array}$}

Soil in hospital premises can be a potential reservoir of organisms with Antimicrobial Resistance (AMR) due to their spread from hospital environment including pre-treated hospital waste. Thus, studying AMR in the soil samples from hospital premises at periodic interval could be helpful in monitoring the trend of its load and spectrum in hospital environment. Prevalence of Extended-Spectrum Beta-Lactamase (ESBL), carbapenemase and New Delhi Metallo-Beta-Lactamase (NDM) varieties of AMR were estimated in Escherichia coli and Klebsiella pneumoniae as indicator organisms in surface soil samples from hospital premises viz. hospital grounds and pedestrian tracks in relation to the pre-monsoon and post-monsoon seasons at an interval of four years between 2014 and 2018. There was significant increase in the prevalence of ESBL (mainly CTX-M variety), carbapenemase and NDM varieties of AMR in isolates from soil samples collected from hospital premises during post-monsoon season compared to pre-monsoon isolates regardless of the year of sampling although monsoon season did not affect the prevalence of AMR in clinical samples processed during the same period. There was gradual rise in resistance to other antibiotics viz. co-trimoxazole, tetracycline, fluoroquinolones and amoxyclav in soil samples collected from hospital premises during the four years interval. Prevalence of various categories of AMR were higher in samples collected during the post-monsoon season compared to prevalence in clinical isolates from hospital attending population during the corresponding period regardless of the year of sampling. Increasing prevalence of various categories of AMR recorded in hospital premises could indicate inadequate containment measures towards prevention of their spread from hospital environment warranting adaption of requisite measures for prevention.

Keywords: ESBL, Carbapenemase, NDM, Soil, Hospital premises 


\section{Introduction}

Soil in hospital premises has been reported to be a potential reservoir of organisms with Antimicrobial Resistance (AMR) due to their spread from hospital environment. ${ }^{1}$ Thus, monitoring of AMR in the hospital premises could be an important measure for reviewing the existing biosafety measures towards containment of infection in the hospital environment. Contaminated soil from hospital premises could also pose a risk for acquisition of AMR by healthy human subjects visiting indoor patients or accompanying patients to outpatient department for treatment. The situation is likely to be aggravated during monsoon season in India due to frequent flooding of hospital premises by rain water facilitating spread of AMR microbes from any breach in hospital waste disposal system..$^{1-4}$

Several decades of therapeutic use of antibiotics for treatment of infections in India has witnessed increasing prevalence of Extended-Spectrum Beta-Lactamase (ESBL) producing and subsequently carbapenemase producing bacteria belonging to Enterobacteriaceae family resulting in gradual narrowing of the therapeutic options. New Delhi Metallo-Beta-Lactamase (NDM) production by enteric organisms, a relatively recent addition to the problem, has now become a global concern. ${ }^{5,6}$ Two organisms of normal gut flora belonging to Enterobacteriaceae family viz. Escherichia coli (E. coli) and Klebsiella pneumoniae ( $K$. pneumoniae) have been commonly selected as indicator organisms to monitor spread of AMR in hospital environment although studies have mostly been limited to single point assessment. ${ }^{7-9}$

A study was undertaken to monitor the change in the prevalence of ESBL, carbapenemase and NDM varieties of AMR in hospital premises over a four years period between 2014 and 2018 and study the effect of monsoon on their load using E. coli and K. pneumoniae as indicator organisms.

\section{Materials and Methods}

\section{Study Location}

The present study was conducted in the department of Microbiology, SGT Medical College Hospital, a 600 bedded newly established multi-specialty hospital located in the peri-urban belt of Haryana state in northern India.

\section{Study Period and Periodicity of Sampling}

The study was prospective in nature conducted in two phases i.e., in 2014 and in 2018. Sampling was carried out weekly for three months (12 weeks) in each year during each of the two monsoon-related seasons identified on the basis of Indian climatic conditions i.e., pre-monsoon (March-May) and post-monsoon (September-November). ${ }^{10}$

\section{Collection of Samples}

Surface soil samples were collected from two categories of locations within hospital premises viz. (i) hospital grounds and (ii) pedestrian tracks used by hospital attending population.

\section{Selection of Sampling Sites and Frequency Surface Soil from Hospital Grounds}

Two parallel longitudinal lines, each at 4 feet and at 10 feet distances, were marked from the four boundary walls of the rectangular hospital block excluding pedestrian tracks. Four equidistant points on the length of each line on the four sides of the hospital block were randomly selected for weekly sampling using computer generated random numbers. Thus, a total of 16 soil samples each were collected at 4 feet and at 10 feet distances from the four sides of the hospital block per week totalling to 192 samples at each of the distances over the period of 3 months (12 weeks) during the pre-monsoon and postmonsoon seasons.

\section{Surface Soil Samples from Pedestrian Tracks}

Two locations at 4 feet and at 10 feet away from hospital building edge were selected on two pedestrian tracks used by the hospital attending population. Three random points across the transverse breadth of the track at 4 feet and 10 feet distances from the hospital building were sampled twice in a week i.e., 6 samples per week each at 4 feet and 10 feet distances on each pedestrian track, totalling to 72 samples/ track/ per season of 12 weeks or total of 144 samples per season from the two selected tracks in each year. Repeat sampling of the pedestrian tracks was carried out after an interval of four years in the same manner during pre-monsoon and post-monsoon seasons of the year 2014 and 2018.

\section{Collection of Samples}

Surface soil samples were collected from each sample collection point covering an approximate area of $10 \mathrm{~cm}$ by $10 \mathrm{~cm}$ square with five longitudinal, five latitudinal and two diagonal strokes using sterile swabs pre-moistened with nutrient broth immediately before use. ${ }^{11}$ After collection of the sample, the swab was placed in polypropylene tube containing $2 \mathrm{ml}$ nutrient broth and transported to laboratory in ice pack within 30 minutes.

Processing of Samples for Screening of ESBL and Carbapenemase Producing E. coli and K. pneumoniae Isolates

Surface soil swabs from hospital premises, collected in nutrient broth were vortexed for 2 mins. Each sample was inoculated in 10 volumes of enrichment broth (LB broth, Sigma Aldrich, USA) followed by overnight aerobic incubation at $37^{\circ} \mathrm{C}$. The enriched sample was plated on a set of four MacConkey agar plates viz. (i) plain MacConkey for isolation of E. coli and K. pneumoniae (ii) two MacConkey 
agar plates, one supplemented with $2 \mu \mathrm{g}$ of cefotaxime per $\mathrm{ml}$ (Mac-CTX) and the other supplemented with $2 \mu \mathrm{g}$ of ceftazidime per $\mathrm{ml}$ (Mac-CAZ), both as screening media for isolation of ESBL producing E. coli (ESBL-EC) as well as ESBL producing $K$. pneumoniae (ESBL-KP) and (iii) one MacConkey agar plate supplemented with $1 \mathrm{mg} / \mathrm{L}$ of ertapenem (MacETP) as screening medium for isolation of carbapenemase producing E. coli (CR-EC) and K. pneumoniae (CR-KP). All the plates were incubated aerobically overnight at $37^{\circ} \mathrm{C}$. Two to three randomly selected lactose fermenting colonies suggestive of $E$. coli or $K$. pneumoniae were picked up from each plate and were subjected to species confirmation using Vitek 2 system (BioMerieux, France) and also to ensure concordance in the species identification as $E$. coli or $K$. pneumoniae in the colonies selected from different plates based on colony morphology. E. coli and K. pneumoniae strains growing in ESBL screening media and in carbapenemase screening media were identified as potential ESBL and carbapenemase producing strains respectively. ${ }^{12,13}$

\section{Antibiotic Sensitivity Testing (AST) of the $E$. coli and $K$. pneumoniae Isolates}

Antibiotic Sensitivity Testing (AST) of the $E$. coli and $K$. pneumoniae isolated on plain MacConkey plates was performed by disc diffusion method and the results were interpreted as per CLSI guidelines. ${ }^{14}$ The following antibiotic discs were used: ampicillin $(10 \mu \mathrm{g})$, amoxicillin-clavulanic acid $(20 / 10 \mu \mathrm{g})$, piperacillin/tazobactam (100/10 $\mu \mathrm{g})$, amikacin $(30 \mu \mathrm{g})$, gentamicin $(10 \mu \mathrm{g})$, cefotaxime $(30 \mu \mathrm{g})$, ceftazidime $(30 \mu \mathrm{g})$, aztreonam $(30 \mu \mathrm{g})$, ciprofloxacin $(5 \mu \mathrm{g})$, ofloxacin $(5 \mu \mathrm{g})$, chloramphenicol $(30 \mu \mathrm{g})$, co-trimoxazole $(25 \mu \mathrm{g})$, ertapenem $(10 \mu \mathrm{g})$, meropenem $(10 \mu \mathrm{g})$, imipenem $(10 \mu \mathrm{g})$, tetracycline $(30 \mu \mathrm{g})$ and tigecycline $(15 \mu \mathrm{g})$.

\section{Phenotypic Confirmatory Tests for ESBL and Carbapenemase Production \\ ESBL Production}

E. coli and $K$. pneumoniae isolates from ESBL screening media i.e., Mac-CTX and Mac-CAZ were subjected to Double Disc Synergy Test (DDST) as phenotypic confirmatory test for ESBL production using ceftazidime $(30 \mu \mathrm{g})$ and ceftazidime plus clavulanic acid ( $30 \mu \mathrm{g}$ plus $10 \mu \mathrm{g}$ ) discs as first pair and cefotaxime $(30 \mu \mathrm{g})$ and cefotaxime plus clavulanic acid (30 $\mu \mathrm{g}$ plus $10 \mu \mathrm{g}$ ) discs as second pair as described earlier. ${ }^{12}$ K. pneumoniae ATCC 700603 and E. coli ATCC 25922 were used as ESBL positive and ESBL negative control strains respectively.

\section{Carbapenemase Production}

$E$. coli and K. pneumoniae isolates from CR screening medium i.e., Mac-ETP were initially subjected to modified Hodge test (MHT) as described earlier. ${ }^{13}$ However, all the
E. coli and K. pneumoniae isolated from the Mac-ETP plate were also subjected to revalidation of carbapenemase production on the basis of Carba-NP test in accordance with new CLSI guidelines. Both the methods employed K. pneumoniae ATCC BAA 1705 and E. coli ATCC 25922 as positive and negative control strains respectively. Only those isolates showing evidence of carbapenemase production by Carba-NP test were considered for further evaluation. ${ }^{14}$

\section{Polymerase Chain Reaction (PCR) for Detection of ESBL Genes and NDM Gene}

\section{ESBL Genes}

PCR assay was done to detect the presence of $b / a_{\text {TEM }^{\prime}}$ $b / a_{\mathrm{SHV}}$ and $b / a_{\mathrm{CTX}-\mathrm{M}}$ genes using specific primers with prepublished sequences viz. ATGAGTATTCAACATTTCCGTG (forward) and TTACCAATGCTTAATCAGTGAG (reverse) for bla ${ }_{\text {TEM, }}$ ATTTGTCGCTTCTTTACTCGC (forward) and TTTATGGCGTTACCTTTGACC (reverse) for blaSHV and TTTGCGATGTGCAGTACCAGTAA (forward) and CGATATCGTTGGTGGTGCCATA (backward) for bla ${ }_{\text {CTX-M. }}$. Three previously confirmed isolates of $E$. coli from the laboratory producing bla $a_{T E M}, b / a_{S H V}, b l a_{C T X-M}$ were used as positive controls. Nuclease-free water without DNA template was included in every PCR assay as negative control. ${ }^{12,15}$

\section{NDM Gene}

PCR for detection of bla ${ }_{\text {NDM }}$ was carried out for carbapenemase producing (Carba-NP positive) stains using primer sequences, forward 5'-ACCGCCTGGACCGATGACCA-3' and reverse 5'-GCCAAAGTTGGGCGCGGTTG-3', which amplified $264 \mathrm{bp}$ fragment of the blaNDM gene as desribed earlier. ${ }^{12}$ The PCR products were purified by PCR purification kit (QIAGEN, Hidden, Germany) and run on gel electrophoresis followed by ethidium staining to confirm specificity of NDM gene by matching with the molecular weight markers.

\section{Collection of Information on Clinical Samples from Hospital Attending Population}

Information on positivity rate of ESBL, CRE, CTX-M and blaNDM genes among $E$. coli and $K$. pneumoniae isolated from clinical specimens processed by the hospital laboratory during the two seasons and years corresponding to the present study i.e., pre-monsoon and post-monsoon seasons in the years 2014 and 2018 along with their antibiotic resistance pattern was collected from the records of a separate ongoing hospital-based surveillance.

\section{Statistical Analysis}

Chi square test was employed to undertake bivariate analysis of categorical variables with Yate's correction for cell values less than 5 . P-value $<0.05$ was considered statistically significant. 


\section{Result}

There was significant increase in the prevalence of various categories of AMR in indicator organisms i.e., E. coli and/ or K. pneumoniae isolated from soil samples in hospital grounds and pedestrian tracks over the four years period between 2014 and 2018 (Tables 1 and 2). In both the years, prevalence of AMR was higher in samples collected during post-monsoon season compared to pre-monsoon season and in samples collected at closer distance from hospital block i.e., $4 \mathrm{ft}$. compared to samples collected at greater distance i.e., $10 \mathrm{ft}$. on hospital grounds as well as on pedestrian tracks. In both the years the prevalence of various categories of AMR in soil samples collected from pedestrian tracks were higher than samples collected from hospital ground at corresponding distances regardless of the season although the difference was not statistically significant. The CTX-M was the predominant type of ESBL regardless of the location, season or year of isolation. However, while isolates in 2014 did not demonstrate any evidence of NDM production, samples collected during 2018 showed emergence of NDM production among the isolates (Table 1 and 2).

The prevalence of ESBL, CRE, CTX-M and NDM gene were recorded in E. coli and/or K. pneumoniae isolates from clinical samples during pre-monsoon as well as post-monsoon seasons were noted to be higher in 2018 compared to the corresponding seasons in the year 2014. However, unlike the soil samples collected from hospital premises including pedestrian tracks, prevalence of various categories of AMR in clinical specimens did not vary between the premonsoon and post-monsoon samples in both 2014 and in 2018 (Table 3).

On comparison, prevalence of various categories of AMR in samples collected from hospital premises were lower than the prevalence of similar categories of AMR in clinical isolates during pre-monsoon period but were higher in post-monsoon period in both the years (Table 1-3).

Table I.Prevalence of various categories of AMR in E. coli and/or K. pneumoniae isolated from surface soil samples in the hospital ground

\begin{tabular}{|c|c|c|c|c|c|}
\hline \multirow{3}{*}{ Location } & \multirow{3}{*}{ Type of AMR } & \multicolumn{4}{|c|}{ Prevalence (\%) of AMR in E. coli and/or K. pneumoniae isolates } \\
\hline & & \multicolumn{2}{|c|}{2014} & \multicolumn{2}{|c|}{2018} \\
\hline & & $\begin{array}{l}\text { Pre-mon } \\
(\mathrm{n}=192)^{* *}\end{array}$ & $\begin{array}{l}\text { Post-mon } \\
(n=192)^{* *}\end{array}$ & $\begin{array}{l}\text { Pre-mon } \\
(n=192)^{* *}\end{array}$ & $\begin{array}{l}\text { Post-mon } \\
(n=192)^{* *}\end{array}$ \\
\hline \multirow{7}{*}{$4 \mathrm{ft}^{*}$} & No of isolates & $18(9.4)$ & $32(16.7)^{\mathrm{a}}$ & $39(20.3)^{b}$ & $52(27.1)^{a, b}$ \\
\hline & ESBL & $06(33.3)$ & $15(46.9)^{a}$ & $18(46.2)^{\mathrm{b}}$ & $35(67.3)^{a, b}$ \\
\hline & CTX-M alone@ & $04(66.7)$ & $11(73.3)$ & $13(72.2)$ & $28(80)$ \\
\hline & $\begin{array}{l}\text { CTX-M with other ESBL } \\
\text { genes } @\end{array}$ & $01(16.7)$ & $03(20)$ & $03(16.7)$ & $05(14.3)$ \\
\hline & Other ESBL genes ${ }^{@}$ & $01(16.7)$ & $01(6.7)$ & $02(11.1)$ & $02(5.7)$ \\
\hline & CRE & $01(5.6)$ & $06(18.8)^{a}$ & $07(17.9)^{b}$ & $17(32.7)^{a, b}$ \\
\hline & NDM & 00 & 00 & $01(2.7)$ & $04(7.7)^{\mathrm{a}}$ \\
\hline \multirow{7}{*}{$\begin{array}{l}10 \mathrm{ft*} \\
(\mathrm{n}=192)\end{array}$} & No. of isolates & $13(6.8)$ & $26(13.5)^{a}$ & $22(11.5)^{b}$ & $38(19.8)^{a, b}$ \\
\hline & ESBL & $04(30.8)$ & $11(42.9)^{\mathrm{a}}$ & $09(40.9)^{\mathrm{b}}$ & $19(50)^{a, b}$ \\
\hline & CTX-M alone@ & $03(75)$ & $8(72.7)$ & $07(77.8)$ & $13(68.4)$ \\
\hline & $\begin{array}{l}\text { CTX-M with other ESBL } \\
\text { genes }\end{array}$ & $01(25)$ & $01(9.1)$ & 01 (11.1) & $04(21.1)$ \\
\hline & Other ESBL genes ${ }^{@}$ & 00 & $01(9.1)$ & $01(11.1)$ & $02(10.5)$ \\
\hline & CRE & 00 & 00 & $01(4.5)$ & $03(7.9)^{a}$ \\
\hline & NDM & 00 & 00 & 00 & $02(5.3)$ \\
\hline
\end{tabular}

Pre-mon $=$ Pre-monsoon, Post - mon $=$ Post-monsoon

*Indicates distance from the edge of the hospital building.

**No of samples processed.

${ }^{\circledR}$ Calculated out of total ESBL producing E. coli and/or K. pneumoniae isolates.

Statistical comparisons:

$\mathrm{a}=$ Significant increase in prevalence, post-monsoon vs. pre-monsoon.

$\mathrm{b}=$ Significant increase in prevalence between years of study in corresponding seasons, 2018 vs. 2014 . 
Table 2.Prevalence of various categories of AMR in E. coli and/or K. pneumoniae isolated from surface soil samples on the pedestrian tracks

\begin{tabular}{|c|c|c|c|c|c|}
\hline \multirow{3}{*}{ Location } & \multirow{3}{*}{ Type of AMR } & \multicolumn{4}{|c|}{ Prevalence of AMR in E. coli and/or K. pneumoniae No. (\%) } \\
\hline & & \multicolumn{2}{|c|}{2014} & \multicolumn{2}{|c|}{2018} \\
\hline & & $\begin{array}{l}\text { Pre-mon } \\
(n=144)^{* *}\end{array}$ & $\begin{array}{l}\text { Post-mon } \\
(n=144) * *\end{array}$ & $\begin{array}{l}\text { Pre-mon } \\
(\mathrm{n}=144)^{* *}\end{array}$ & $\begin{array}{l}\text { Post-mon } \\
(\mathrm{n}=144)^{* *}\end{array}$ \\
\hline \multirow{7}{*}{$4 \mathrm{ft}^{*}$} & No of isolates & $19(13.2)$ & $31(21.5)$ & $37(25.7)^{b}$ & $45(31.3)$ \\
\hline & $\mathrm{ESBL}$ & $08(42.1)$ & $16(51.6)$ & $21(56.8)^{b}$ & $32(71.1)^{b}$ \\
\hline & CTX-M alone ${ }^{@}$ & $04(50)$ & $11(68.8)^{\mathrm{a}}$ & $16(76.2)$ & $26(81.3)$ \\
\hline & CTX-M with other ESBL genes ${ }^{\circledR}$ & $03(37.5)$ & $05(31.2)$ & $04(9.5)$ & $05(15.6)$ \\
\hline & Other ESBL genes@ & $01(12.5)$ & 00 & $01(4.7)$ & $01(3.1)$ \\
\hline & CRE & $01(5.2)$ & $04(12.9)$ & $08(21.6)^{b}$ & $16(35.6)^{b}$ \\
\hline & NDM & 00 & 00 & $01(2.7)$ & $06(13.3)^{\mathrm{a}}$ \\
\hline \multirow{7}{*}{$10 \mathrm{ft}^{*}$} & No. of isolates & $14(9.7)$ & $20(17.4)$ & $29(20.1)^{b}$ & $35(24.3)^{b}$ \\
\hline & ESBL & $06(42.9)$ & $12(48)$ & $15(51.7)^{\mathrm{b}}$ & $20(57.1)$ \\
\hline & CTX-M alone ${ }^{@}$ & $04(66.7)$ & $9(75)$ & $12(80)$ & $15(75)$ \\
\hline & CTX-M with other ESBL genes@ & $01(16.7)$ & $2(16.7)$ & $01(6.7)$ & $05(25)$ \\
\hline & Other ESBL genes@ & $01(16.7)$ & $01(8.3)$ & $02(13.3)$ & 00 \\
\hline & CRE & $01(7.1)$ & $03(15)$ & $03(10.3)$ & $09(25.7)^{b}$ \\
\hline & NDM & 00 & 00 & $01(3.4)$ & $03(8.6)^{a}$ \\
\hline
\end{tabular}

Pre-mon = Pre-monsoon; Post-mon = Post-monsoon .

Notes:

* Indicates distance from the edge of the building towards pedestrian tracks.

${ }^{\circledR}$ Calculated out of total ESBL producing E. coli and/or K. pneumoniae isolates.

Statistical comparisons:

$a=$ Significant increase in prevalence, post-monsoon vs. pre-monsoon.

$b=$ Significant increase in prevalence between years of study in corresponding seasons, 2018 vs. 2014 .

Table 3.Prevalence of various categories of AMR in $E$. coli and/or $K$. pneumoniae isolated from clinical specimens

\begin{tabular}{|c|c|c|c|c|c|}
\hline \multirow{3}{*}{$\begin{array}{l}\text { Source of } \\
\text { samples }\end{array}$} & \multirow{3}{*}{ Type of AMR } & \multicolumn{4}{|c|}{ Prevalence (\%) of AMR in E. coli and/or K. pneumoniae } \\
\hline & & \multicolumn{2}{|c|}{2014} & \multicolumn{2}{|c|}{2018} \\
\hline & & $\begin{array}{l}\text { Pre-mon } \\
(n=1652)^{*}\end{array}$ & $\begin{array}{l}\text { Post-mon } \\
(n=1857)^{*}\end{array}$ & $\begin{array}{l}\text { Pre-mon } \\
(n=2456)^{*}\end{array}$ & $\begin{array}{c}\text { Post-mon } \\
(2789)^{*}\end{array}$ \\
\hline \multirow{7}{*}{$\begin{array}{c}\text { Clinical } \\
\text { specimens }\end{array}$} & No. of isolates & $106(6.4)$ & $132(7.1)$ & $325(13.2)^{a}$ & $392(14.1)^{\mathrm{a}}$ \\
\hline & ESBL & $45(42.5)$ & $61(46.2)$ & $181(55.7)^{\mathrm{a}}$ & $225(57.4)^{\mathrm{a}}$ \\
\hline & CTX-M alone ${ }^{@}$ & $33(73.3)$ & $47(77)$ & $147(81.2)$ & $186(82.7)^{\mathrm{a}}$ \\
\hline & CTX-M with other ESBL genes ${ }^{@}$ & $07(15.6)$ & $09(14.8)$ & $34(18.8)$ & $24(10.7)$ \\
\hline & Other ESBL genes ${ }^{@}$ & $05(11.1)$ & $05(8.2)$ & 00 & $15(6.7)$ \\
\hline & CRE & $03(2.8)$ & $05(3.8)$ & $29(8.9)^{a}$ & $43(10.9)^{a}$ \\
\hline & NDM & 00 & 00 & $04(1.2)$ & $06(1.5)$ \\
\hline
\end{tabular}

Pre-mon = Pre-monsoon; Post-mon = Post-monsoon

Notes:

*Indicates number of clinical specimens processed

${ }^{\circledR}$ Calculated out of total ESBL producing E. coli and/or K. pneumoniae isolates

Statistical comparisons:

There was no statistical difference in prevalence, post-monsoon vs. pre-monsoon samples.

a=Significant increase in prevalence between years of study in corresponding seasons, 2018 vs. 2014. 
Antibiotic sensitivity pattern of the E. coli and/or $K$. pneumoniae isolated from hospital premises including pedestrian tracks showed an increase in the prevalence of resistance to cephalosporin and carbapenem group of antibiotics over the study period. An increasing prevalence of resistance was also noted for other antibiotics viz. cotrimoxazole, tetracycline, fluoroquinolones and amoxyclav during the same period. Pattern of resistance to various antibiotics among the in E. coli and/or K. pneumoniae isolates from hospital premises including pedestrian tracks were similar to that observed in clinical isolates (Table 4). prevalence of various categories of AMR in soil samples collected at $4 \mathrm{ft}$ distance compared to that collected at 10 $\mathrm{ft}$ distance, regardless of the year of collection, reflects dissemination of AMR from hospital environment.

However, the salient observation in the present study was higher prevalence of various categories of AMR in indicator organisms in soil samples from hospital premises during the post-monsoon period compared to similar isolates from corresponding locations during pre-monsoon period in both the years of sampling suggesting additional contribution of

Table 4.Profile of resistance to various antibiotics in $E$. coli and/or K. pneumoniae isolates from various sources

\begin{tabular}{|c|c|c|c|c|c|c|}
\hline \multirow{4}{*}{ Antibiotic } & \multicolumn{6}{|c|}{$\begin{array}{l}\text { Antibiotic resistance profile of } E \text {. coli and/or } K \text {. pneumoniae isolates } \\
\text { from various samples }\end{array}$} \\
\hline & \multicolumn{2}{|c|}{ Clinical samples } & \multicolumn{2}{|c|}{$\begin{array}{l}\text { Soil samples from hospital } \\
\text { premises }\end{array}$} & \multicolumn{2}{|c|}{$\begin{array}{l}\text { Soil samples from the } \\
\text { pedestrian tracks }\end{array}$} \\
\hline & $2014(n=238)^{*}$ & $2018(n=717)^{*}$ & $2014(n=89) *$ & $2018(n=151)^{*}$ & $2014(n=84) *$ & $2018(n=146)^{*}$ \\
\hline & No. (\%) & No. (\%) & No. (\%) & No. (\%) & No. (\%) & No. (\%) \\
\hline AMP & $193(81.1)$ & 631 (88.1) & $74(83.1)$ & 135 (89.4) & $72(85.7)$ & $133(91.1)$ \\
\hline AMC & $108(45.4)$ & $467(65.1)^{a}$ & $50(56.2)$ & $103(68.2)^{a}$ & $50(59.5)$ & $105(71.9)^{\mathrm{a}}$ \\
\hline PIT & $58(24.4)$ & $163(22.7)$ & $22(24.7)$ & $39(25.8)$ & $24(28.6)$ & $35(24)$ \\
\hline $\mathrm{AK}$ & 45 (18.9) & $120(16.7)$ & $20(22.5)$ & $31(20.5)$ & $24(28.6)$ & $32(21.9)$ \\
\hline GEN & $63(26.5)$ & $149(20.8)$ & $28(31.5)$ & $46(30.5)$ & $30(35.7)$ & $49(33.6)$ \\
\hline CTX & $109(45.8)$ & $411(57.3)^{a}$ & 37 (41.6) & $83(55)^{a}$ & $36(42.9)$ & $85(58.2)^{a}$ \\
\hline CAZ & 105 (44.1) & $404(56.3)^{a}$ & 35 (39.3) & $83(54.9)^{a}$ & 36 (42.9) & $84(57.5)^{a}$ \\
\hline AT & $108(45.4)$ & $407(56.8)$ & $35(39.3)$ & $82(54.3)$ & 35 (41.7) & $85(58.2)$ \\
\hline ETP & $11(4.6)$ & $72(10)^{a}$ & $07(7.9)$ & $28(18.5)^{a}$ & $07(8.3)$ & $36(24.7)^{a}$ \\
\hline IPM & $13(5.5)$ & $76(10.6)^{a}$ & $10(11.2)$ & $30(19.9)^{a}$ & $07(8.3)$ & $38(26)^{a}$ \\
\hline MRP & $14(5.9)$ & $76(10.6)^{a}$ & 09 (10.1) & $28(18.5)^{a}$ & $08(9.5)$ & $38(26)^{a}$ \\
\hline COT & $238(60.5)$ & $608(84.8)^{\mathrm{a}}$ & $58(65.2)$ & $132(87.4)^{\mathrm{a}}$ & $53(63.1)$ & $131(89.7)^{\mathrm{a}}$ \\
\hline$C$ & $124(52.1)$ & $535(74.6)^{a}$ & 39 (43.8) & $76(50.3)$ & $38(45.2)$ & $79(54.1)$ \\
\hline CIP & $117(49.2)$ & $525(73.2)^{a}$ & $56(62.9)$ & $119(78.8)^{a}$ & $54(64.3)$ & $118(80.8)^{a}$ \\
\hline OF & $108(45.4)$ & $408(56.9)^{a}$ & $41(46.1)$ & $114(75.5)^{\mathrm{a}}$ & $40(47.6)$ & $118(80.8)^{a}$ \\
\hline TE & $138(58)$ & $467(65.1)^{a}$ & $60(67.4)$ & $117(77.5)^{a}$ & $55(65.5)$ & $115(78.8)^{a}$ \\
\hline
\end{tabular}

* Total isolates in the year (pre-monsoon and post-monsoon combined)

' $a$ ' indicates significant rise $(p<0.05)$ in 2018 compared to 2014

$\mathrm{AMP}=$ Ampicillin, $\mathrm{AMC}=$ Amoxyclav, $\mathrm{PIT}=$ Piperacillin/tazobactam, $\mathrm{AK}=$ Amikacin, $\mathrm{GEN}=$ Gentamicin, $\mathrm{CTX}=$ Cefotaxime, $\mathrm{CAZ}=\mathrm{Ceftazidime}$, $\mathrm{AT}=$ Aztreonam, ETP = Ertapanem, IPM = Imipenem, MRP = Meropenem, C = Chloramphenicol, COT = Co-trimoxazole, CIP = Ciprofloxacin, OF = Ofloxacin, TE = Tetracycline

Note: All the isolates were susceptible to tigecycline.

\section{Discussion}

Increasing prevalence of AMR in the soil samples collected in 2018 compared to that collected in 2014, regardless of the sampling location indicate gradual rise in the prevalence of AMR in hospital environment over the years. Higher monsoon to the load of AMR in soil samples. In northern part of India, rainfall is reasonably heavy during monsoon season resulting in frequent flooding of ground soil. An upcoming health care set up as the present one with numerous subsurface reservoirs in the hospital premises receiving untreated hospital sewage with improperly 
covered lids, or breach in the integrity of the sewage collection channel may provide opportunity for overflow of untreated sewage into surrounding areas. Magnitude of AMR in pre-treated hospital sewage is a reflection of its load in hospitalised patients and in hospital environment. ${ }^{16}$ However, there are several factors that may amplify the prevalence of AMR in sewage. Firstly, the hospital sewage contains various antibiotics from hospital usage that can create pressure towards emergence and amplification of resistant bacteria. ${ }^{17}$ Secondly, various categories of AMR evaluated in the present study i.e., ESBL, carbapenemase and NDM-1 are commonly carried on plasmids. ${ }^{18}$ In-vitro conjugation experiments have shown that plasmid mediated resistance to these antibiotics can easily be transferred to $E$. coli as recipient from sewage isolates e.g. Acineotbacter baumannii as donor. ${ }^{19}$ Moreover, presence of biofilm in sewage has been shown to be a favourable environment for such transfer ${ }^{20}$ although transfer has been shown even in environmental surface waters. ${ }^{9}$ Higher prevalence of $\mathrm{AMR}$ in pedestrian tracks compared to the samples from hospital premises at corresponding distances could be due to additional contribution by the movement of people visiting the hospital.

One observation in our study was inability to record any seasonal difference in the prevalence of AMR in the isolates from hospital attending population in both the years. Admittedly, this could be due to difference in profile of hospital attending population in terms of many variables like age, sex, clinical diagnosis and nature of specimens that were not taken into account in the present study. There are reports suggesting lack of perceptible difference in magnitude of communicable diseases in rural population. While acute respiratory infections and pneumonia are reported to be common in pre-monsoon summer days, diarrhoeal diseases are reported to be more common during monsoon seasons in rural India. ${ }^{21,22}$ However, hospital attending population in the present study represented a small fraction of the disease burden in the rural community known to seek treatment from non-health care sources that could be another variable responsible for lack of perceptible seasonal difference in the isolation rates of the two organisms observed in the present study.

The significant rise in the prevalence of resistance to some of the non-beta-lactam antibiotics among the E. coli and/ or $K$. pneumoniae isolates over the study period reflects continued increase in the usage of these antibiotics, driven by cost factors and over the counter availability. ${ }^{23-25}$ Marginal but statistically insignificant increase in the prevalence of resistance to carbapenem group of antibiotics detected in AST compared to that detected by Carba-NP test could be due to resistance mechanisms other than carbapenemase production e.g. efflux pump or chromosomal porin mutation by the carbapenem resistant by additional isolates. ${ }^{26}$
Comparable resistance pattern in the indicator organisms between the hospital isolates and the isolates from the hospital premises strengthens the possibility of spread of AMR from hospital environment. To the best of our knowledge, this is the first longitudinal study from India attempting to monitor the trend of AMR in hospital premises highlighting the need for periodic monitoring of sewage disposal system and biosafety measures.

\section{Conclusion}

The present study provides evidence in favor of spread of AMR from hospital environment including sewage effluents to the soil in the premises of the hospital following monsoon season. Periodic monitoring of AMR in hospital premises may be helpful in adapting necessary measures to prevent leakage or overflow as well as adherence to safe disposal of hospital wastes.

\section{Funding}

This research project received no financial grant from any funding agency.

\section{Conflict of Interest: None}

\section{References}

1. Modi G, Mishra SK, Modi BS et al. Production and characterization of multiple drug resistant cultures isolated from hospital premises. Indian J Life Sci 2013; 3: 7-14.

2. Lamba M, Graham DW, Ahammad SZ. Hospital waste water releases carbapenem resistance pathogens and genes in urban India. Environ Sci Technol 2017; 51: 13906-12.

3. Taneja N, Sharma M. Antimicrobial resistance in the environment: The Indian scenario. Indian J Med Res 2019; 149: 119-28.

4. Nicolle LW. Infection control programmes to contain antimicrobial resistance. WHO/CDS/CSR/DRS/2001.7, World Health Organisation, 2001.

5. Kumaraswamy KK, Toleman MA, Walsh TR et al. Emergence of a new antibiotic resistance mechanism in India, Pakistan,and the UK: a molecular, biological and epidemiological study. Lancet Infect Dis 2010; 10: 597-602.

6. Kumar SG, Adithan C, Harish BN, et al. Antimicrobial resistance in India: A review. J Nat Sci Biol Med 2013; 4: 286-91.

7. Jarvis WR, Munn VP, Highsmith AK et al. The epidemiology of nosocomial infections caused by Klebsiella pneumoniae. Infect Cont 1985; 6: 68-74.

8. Podschun R, Ullmann U. Klebsiella spp. as nosocomial pathogens: epidemiology, taxonomy, typing methods and pathogenicity factors. Clin Microbiol Rev 1998; 11: 589-603.

9. Haberacht HB, Nealon NJ, Gilliand JR et al. Antimicrobial- 
resistant Escherichia coli from environmental waters in northern Colorado. J Environ Public Health 2019.

10. India Meteorological Department, Ministry of Earth Sciences, Government of India. Available from: https:// mausam.imd.gov.in/imd_latest/contents/monsoon. php,

11. Freeman JC, Nimmo J, Gregory E et al. Predictors of hospital surface contamination with ESBL-producing Escherichia coli and Klebsiella pneumoniae: patient and organism factors. Antimicrob Resist Infect Cont 2014; $3: 5$.

12. Devi LS, Broor S, Rautela RS et al. Increasing prevalence of Escherichia coli and Klebsiella pneumoniae producing CTX-M type extended-spectrum beta-lactamase (CTX$\mathrm{M}-\mathrm{ESBL}$ ), carbapenemase and NDM-1 in patients from a rural community with community acquired infections: A three years study. Int J Appl Basic Med Res 2020; 10(3): 156-163.

13. Devi LS, Broor S, Chakravarti A et al. Livestock manure as potential reservoir of CTX-M type extendedspectrum $\beta$-lactamase producing Escherichia coli and Klebsiella pneumoniae associated with carbapenemase production. J Pure Appl Microbiol 2020; 14: 171-181.

14. Clinical Laboratory Standard Institute. Performance Standards for Antimicrobial Susceptibility Testing, $29^{\text {th }}$ Informational Supplement. M100-S27, 2019. Pennsylvania, Wayne, USA.

15. Sidjabat HE, Paterson DL, Adams-Haduch JM et al. Molecular Epidemiology of CTX-M-Producing Escherichia coli Isolates at a Tertiary Medical Centre in Western Pennsylvania. Antimicrob Agents Chemother 2009; 53: 4733-9.

16. Prado T, Pereira WC, Silva DM et al. Detection of extended spectrum beta-lactamase producing Klebsiella pneumoniae in effluents and sludge of a hospital sewage treatment plant. Lett Appl Microbiol 2008; 46: 136-41.

17. Bengtsson-Palme J, Larsson DJ. Concentrations of antibiotics predicted to select for resistant bacteria: proposed limits for environmental regulation. Environ Int 2016; 86: 140-149.

18. Kazemian $\mathrm{H}$, Heideri $\mathrm{H}$, Ghanavati R et al. Phenotypic and genotypic characterisation of ESBL, Amp-C and carbapenamase producing Klebsiella pneumoniae and Escherichia coli isolates. Med Princ Pract 2019; 28: 547-54.

19. Zhang C, Qiu S, Wang Y et al. Higher isolation of NDM-1 producing Acinetobacter baumannii from the sewage of the hospitals in Beijing. PLoS ONE 2013; 8: e64857.

20. Tanner WD, Atkinson RM, Goel RK et al. Horizontal transfer of the blaNDM-1 gene to Pseudomonas aeruginosa and Acinetobacter baumannii in biofilms. FEMS Microb Lett 2017; 364: fnx048.
21. Sharma MK, Bhatnagar T, Goel NK et al. Operationalization of surveillance of communicable diseases in Chandigarh. J Commun Dis 2005; 37: 197 202.

22. Kumari R, Nath B, Midha T et al. Morbidity profile and seasonal variation of diseases in a primary health center in Kanpur district: a tool for the health planners. J Family Med Prim Care 2012; 1: 86-91.

23. Ahmad A, Patel I, Mohanta G et al. Evaluation of Selfmedication practices in rural area of town Sahaswan at Northern India. Ann Med Health Sci Res 2014; 4 (Suppl 2): S73-8.

24. Nafade V, Huddart S, Sulis G et al. Over-the-counter antibiotic dispensing by pharmacies: a standardized patient study in Udupi district, India. BMJ Glob Health 2019; 4: e001869.

25. Alvarez-Uria G, Zacharia S, Thomas D. High prescription of antimicrobials in a rural district hospital in India. Pharm Pract 2014; 12: 384.

26. Lutgring JD, Limbago BM. The problem of carbapenamase-producing carbapenem-resistant Enterobacteriaceae detection. J Clin Microbiol 2016; 54: 529-34. 